\title{
Use of Natural Gas in Motor Transport as a Strategic Reference Point for Improving the Environmental Situation in Cities
}

\section{E. Chikishev and I. Anisimov}

Department of Motor Transport Operation, Industrial University of Tyumen, 625000, Tyumen, Russia

\section{Abstract}

The paper presents a brief analysis of the problem of environmental pollution by motor transport. Some ways of reducing the harmful effect of transport are presented. Russian legislation on the use of natural gas is analyzed. It is established that the development of the gas-engine infrastructure near major highways and cities is the

Corresponding Author: E. Chikishev chikishev_e@mail.ru Received: 10 February 2018 Accepted: 14 April 2018 Published: 7 May 2018

Publishing services provided by Knowledge

(c) E. Chikishev and I.

Anisimov. This article is

distributed under the terms of

the Creative Commons

Attribution License, which permits unrestricted use and redistribution provided that the original author and source are credited.

Selection and Peer-review under the responsibility of the RFYS Conference Committee. most urgent issue. The criteria that must be met for the successful construction of a branched network of natural gas vehicle refueling stations are given. On the example of the Russian city of Tyumen, an experiment was conducted to account for transit traffic passing through its highways. It is concluded that improvement of the ecological situation is an important aspect of the sustainable urban development. And the actual factor that will reduce the harmful impact of transport on the environment is the use of a more environmentally friendly alternative fuel - natural gas. And to expand its use, a rational territorial and quantitative location of the natural gas vehicle refueling station network is necessary.

\section{Introduction}

Global energy consumption is growing year by year. The most rapid growth in the use of energy resources is observed in China, India, the United States and Russia, as well as the Middle East, Africa and Latin America [1]. At the same time, it is known that fossil sources account for about $80 \%$ of the total world energy consumption, the main being oil and gas. A significant part of these hydrocarbons is used in the operation of vehicles. It is transport that is one of the main anthropogenic sources of the environmental pollution, the number of which in the world is already over 1 billion, and annually is growing steadily. Against this background, many countries are adopting a number of legislative initiatives to reduce the harmful impact of cars on the environment. To support the commitment of countries to reduce the harmful effects of 
human activities, it can be noted, for example, that during 2016 many countries signed the Paris Agreement, which at the end of 2015 was preceded by the 21st Conference (COP 21) of the United Nations Framework Convention on Climate Change.

The purpose of the conference was to sign an international agreement to hold the increase in the global average temperature to well below $2^{\circ} \mathrm{C}$ by 2100 , applicable to all countries. 175 signatories have already signed the Paris Protocol, including the United Kingdom, China, Russia, the United States, France, etc., thus confirming the importance of environmental issues and climate change around the world. The agreement went into effect on November 4, 2016 after its ratification by over 55 countries, together accounting for more than $55 \%$ of greenhouse gas emissions. At the national level, there are also laws that are designed to reduce the harmful impact of transport on the environment. They include:

1. The increase of environmental requirements for vehicles operating on conventional types of fuel (gasoline, diesel). For example, the EU has some of the most stringent restrictions on $\mathrm{CO}_{2}$ emissions in the world. By 2020, carbon emissions from new vehicles should be reduced to $95 \mathrm{~g} / \mathrm{km}$. In the US and Japan, there are similar programs for reducing GHG emissions [2]. However, if in the EU countries, the USA, Japan, etc. $\mathrm{CO}_{2}$ emissions are controlled along with carbon monoxide (CO), hydrocarbons (HC), nitrogen oxides (NOx) and soot, in Russia, when estimating the component composition of exhaust gases, $\mathrm{CO}_{2}$ is not taken into account at all $[3,4]$. For Russia, this issue is very urgent, since in 2014 we entered the top five countries in terms of $\mathrm{CO}_{2}$ emissions in the world [5]. In the country, 1,766,000 $\mathrm{kt}$ of $\mathrm{CO}_{2}$ is released annually as a result of human activities. A significant part of these emissions is accounted for motor transport.

2. The expansion of the use of alternative sources of fuel, such as: gas, electricity, biofuel, hydrogen, etc. These fuels are already widely used in a number of countries. And natural gas is the most commonly used one. According to NGV Journal [6] in the world as of early 2017, there are more than 22 million gas cylinder vehicles (GCV) using natural gas as the primary fuel. This accounts for $2 \%$ of the total world vehicle fleet. In addition, the world fleet of such GCV annually increases by $30 \%$ [6]. The world leaders in terms of the number of GCV and the number of natural gas vehicle refueling stations (NGV RS) are Argentina, Brazil, Germany, India, Iran, Italy, China, Colombia, Pakistan, USA, Thailand and others [6]. Against this background, studies of the use of natural gas on vehicles are relevant [7-9]. Moreover, a lot of experiments have confirmed that when burning 
natural gas in automobile engines, less harmful substances are released with exhaust gases compared to conventional petroleum fuels - gasoline and diesel [8-12 et al]. In addition, in all countries of the world gas fuel is much cheaper in comparison with gasoline and diesel (as a rule, by 2-3 times).

3. Promoting the use of public transport and many others

\section{The use of natural gas in motor transport in Russia}

Of all the available alternative fuel sources for motor transport in Russia, the use of natural gas is the most relevant. The country has the world's largest reserves of this fossil fuel (24.6\%) and is the second largest in its extraction (18\%) [13]. Also at the national and regional levels, a number of legislative initiatives have been adopted, which in the near future should increase natural gas consumption in motor transport both in compressed natural gas (CNG) and liquefied natural gas (LNG)) states. And a pervasive construction of gas refueling stations should play the main role in increasing the consumption of this hydrocarbon by vehicles. In this paper we will only consider CNG RS.

The basic documents adopted recently and designed to significantly expand the use of natural gas in the Russian transport sector are:

1. Act No. 261-FZ "On Energy Saving and on Improving Energy Efficiency and on Amending Certain Legislative Acts of the Russia" of 23.11.2009 (as amended on 04.11.2014 and 29.12.2014). 2. The National Program of the Russia "Energy Efficiency and Energy Sector Development" No. 321 of 15.04.2014 (as amended by the RF Government Decree No.116 of 31.01.2017). 3. The RF Government Order No. 767-r of 13.05.2013 "On regulating relations in the sphere of the use of gas motor fuel, including natural gas as motor fuel". 4. Also, based on the list of instructions of the President of the Russia No. Pr-1298 of June 11, 2013, instructions of the Government of the Russia No. AD-P9-4314 of June 24, 2013 and a comprehensive plan of measures to expand the use of gas as motor fuel, approved by the Government of the Russia on November 14, 2013, No. 6819p-P9, a draft Decree of the Government of the Russia "On the approval of the national program of the Russia "Introduction of gas-engine technology with separation into subprograms for motor vehicles and others" (Prepared by the Ministry of Transport of Russia on 18.05.2016) was issued.

Based on the analysis of the given documents and a number of other legislative federal and regional initiatives, it can be concluded that the number of GCV and gas 
refueling stations in the near future in Russia, as in a number of other countries, should grow rapidly. However, according to a number of sources [14, 15 et al], the development of the gas-engine industry and the growth of the GCV fleet requires an extensive infrastructure of gas refueling stations. For example, CNG RS are concentrated mainly in the European part of Russia and their quantity is clearly not enough to increase consumption of gas fuel in these regions in particular, and throughout the country as a whole. According to NGVjournal data, as of late 2016 only 253 gas CNG RS were commissioned in Russia. Mostly, natural gas refueling stations are distributed in the following Federal Districts (FD) of Russia (the actual number may slightly differ from the data presented): 1. Volga FD - 62; 2. Central FD - 54; 3. Ural FD - 42; 4. Southern FD - 35; 5. North-Caucasian FD - 24.

From a technical point of view, a small number of CNG RS in the remaining Federal Districts can be explained by a number of reasons, among which the main ones are: 1. poor branching (or total absence) of gas pipelines; 2 . significant areas of the given FD; 3 . problematic use of GCV running on natural gas in low-temperature air conditions, since the cold-climate zone occupies the largest part of the territory of Russia - about 70\%. However, according to [16], it is established that a heated gas engine can be operated even at temperatures below $-30^{\circ} \mathrm{C}$. Thus, the expansion of the use of natural gas in motor transport through a rational quantitative and territorial location of gas stations is relevant for Russia, especially in Western and Eastern Siberia, as well as in the Far East.

\section{The basic requirements for the construction sites of CNG RS}

In order to build a CNG RS, the main condition is a gas pipeline. Thus, after analyzing the branching of Russian gas pipelines and having established that their length is much larger in the European part of the country than in the eastern regions, it is possible to establish a similar pattern for gas refueling stations. By the way, there are no CNG RS between the West-Siberian cities of Tyumen and Novosibirsk (distance $1278 \mathrm{~km}$, federal highway P402-P254). And in the Siberian and Far-Eastern Federal Districts, in total there are no more than 20 CNG RS. It is logical that it is rational and safe to locate such stations (and related infrastructure) primarily in the places of the largest flow of vehicles - in cities and along the main highway routes [14, 17]. In this case, it is necessary to comply with fire safety and standard distances from CNG RS to the surrounding objects in accordance with SP 156.13130.2014 "Vehicle refueling stations" 
(order of the Ministry of Emergency Situations of Russia No. 221 of May 5, 2014). Another document that went into effect on May 3, 2015 regulating the construction of CNG RS in Russia is the Rostechnadzor Order No. 559 of 11.12.2014 "Safety Rules for Gas-Engine Fuel Vehicle Refueling Stations".

In [18] we selected for analysis an intensively developing Russian city of Tyumen with a population of about 700 thousand inhabitants and put forward the proposed construction sites for CNG RS. The proposed options are based on the branching of the city's gas transmission system, as well as the amount of potential city vehicles that can be converted to work on natural gas. In the city, two gas distribution stations (GDS) and about 30 gas control points(GCP) operate, the total length of gas pipelines is more than $1000 \mathrm{~km}$, and the throughput is more than 1 million m3 of gas a day (daily for the needs of Tyumen 1 million $\mathrm{m}_{3}$ of gas is supplied). In view of an extensive branching of gas pipelines, it is possible to locate the CNG RS in many of its parts. However, according to the SP 156.13130.2014, it is almost impossible to locate CNG RS in the central parts of the city. In addition, CNG RS are proposed to be installed so that they can be used by transit transport. But in [18], when calculating the optimal performance of CNG RS, transit transport was not taken into account.

Taking into account all the factors considered, it can be noted that in order to determine the necessary number of CNG RS in cities and their location, as well as productivity, in addition to the calculation of transit transport, it is necessary to take into account a number of previously identified factors $[17,18]$ : 1 . The branching of the gas transportation system in the settlement (the number and geographical location of gas distribution stations (GDS) and gas control points (GCP), the length of gas pipelines and their throughput, the distance from the main highways). 2. Requirements for fire safety in terms of remoteness of CNG RS from various objects of urban infrastructure. 3. The number of major highways passing through the settlement. 4. The number of potential urban vehicles that can be converted to work on CNG. 5. The availability and location of existing CNG RS.

Based on the basic requirements for the CNG RS construction sites in cities and urban agglomerations, and considering the predicted increase in the number of vehicles using gas fuels to be supplied by refueling stations, observations were made, the results of which allowed us to substantiate the location of refueling stations in the territories adjacent to the city of Tyumen. 


\section{The results of observations of the hourly traffic intensity at the entrances to Tyumen}

6 places were selected for the investigation on the way out of Tyumen along the main haighways, namely E22 (bypass road), P351 (Moscovskiy tract), P404 (Tobolskiy tract), «Tyumen-Kurgan», P402 (Yalutorovskiy tract), P401 (Irbitskiy tract). The account of transit transport was carried out in March 2017 on weekdays (from Monday to Thursday) at morning and evening "rush hours" from 7:00 to 9:00 and from 17:00 to 19:00. The average intensity of the traffic flow was determined, both at the entrance to and exit from Tyumen by such means of transport as trucks, cars and buses.

Results of an experiment on highway P402 aren't given in this research for the reason that on the way out of Tyumen on $11 \mathrm{~km}$. the CNG RS is already functioning (at the moment is the only refueling station with natural gas in the city). And results of observations on highway P401 aren't given for the reason that there the lowest traffic flow from 6 surveyed areas is established (including almost total absence of buses). As a result of processing the results of observations, the following average values were obtained presented in Table 1.

As a result of observations, it is established that on E22, P351 and Tyumen-Kurgan highways, the morning traffic prevails over the evening traffic by $12 \%, 16 \%$ and $19 \%$, respectively. And on the $\mathrm{P}_{404}$ highway, on the contrary, the evening traffic is $14 \%$ higher compared to the morning observations. The total intensity of traffic in the morning and evening "rush hours" is presented in Table 2.

Next, we determine the approximate daily traffic flow in the directions. On the basis of studies on the traffic intensity of vehicles presented in [19], we predict an approximate 12-hour traffic flow. This work notes that in the analysis of 4 cities the difference in traffic intensity in the morning, afternoon and evening rush hours at the exit from the city varies only within $2 \%$. And the share of 12 -hous traffic intensity in the daily flow changes by less than $10 \%$ - from 80 to $72 \%$. Basis of this, it can be assumed that in the directions studied, the traffic flow will also not change significantly in the 12-hour range (from 7 to 19 hours). Accordingly, in the 12-hour range (from 19 to 7 ), $30 \%$ of the daily flow can be taken. Thus, the approximate daily number of vehicles in the directions will look as follows (Table 3 ).

Next, we predict how many of the counted vehicles can potentially be converted to run on natural gas. Taking into account the RF Government Order No. 767-r, analyzed earlier, by 2020 in Tyumen (population of about 700 thousand people) up to $30 \%$ of 
TABLE 1: Average hourly intensity at the morning (7:00-9:00) and at the evening (17:00-19:00) "rush hour".

\begin{tabular}{|c|c|c|c|c|c|c|}
\hline \multirow[b]{2}{*}{ Direction } & \multicolumn{3}{|c|}{ The morning "rush hour" (7:00-9:00) } & \multicolumn{3}{|c|}{ The evening "rush hour" (17:00-19:00) } \\
\hline & Cars pcs. & Trucks pcs. & Buses pcs. & Cars pcs. & Trucks pcs. & Buses pcs. \\
\hline \multicolumn{7}{|c|}{ 1. At the exit from Tyumen on the highway E22 (bypass road) } \\
\hline To the city & 592 & 92 & 20 & 491 & 76 & 17 \\
\hline From the city & 295 & 57 & 11 & 308 & 29 & 20 \\
\hline Total & 887 & 149 & 31 & 799 & 105 & 37 \\
\hline \multicolumn{7}{|c|}{ 2. At the exit from Tyumen on the highway P351 (Moscovskiy highway) } \\
\hline To the city & 1392 & 157 & 28 & 632 & 100 & 20 \\
\hline From the city & 701 & 80 & 44 & 1076 & 152 & 28 \\
\hline Total & 2093 & 237 & 72 & 1708 & 252 & 48 \\
\hline \multicolumn{7}{|c|}{ 3. At the exit from Tyumen on the highway $\mathrm{P}_{404}$ (Tobolskiy highway) } \\
\hline To the city & 741 & 76 & 21 & 984 & 88 & 20 \\
\hline From the city & 840 & 132 & 24 & 876 & 124 & 28 \\
\hline Total & 1581 & 208 & 45 & 1860 & 212 & 48 \\
\hline \multicolumn{7}{|c|}{ 4. At the exit from Tyumen on the highway Tyumen-Kurgan } \\
\hline To the city & 392 & 16 & 12 & 332 & 8 & 4 \\
\hline From the city & 415 & 12 & 4 & 320 & 20 & 3 \\
\hline Total & 807 & 28 & 16 & 652 & 28 & 7 \\
\hline
\end{tabular}

TABLE 2: The total intensity of traffic in the directions.

\begin{tabular}{|l|c|c|c|c|}
\hline Highway & Cars pcs. & Trucks pcs. & Buses pcs. & Total \\
\hline P351 & 3801 & 489 & 120 & 4410 \\
\hline P404 & 3441 & 420 & 93 & 3954 \\
\hline E22 & 1686 & 254 & 68 & 2008 \\
\hline Tyumen-Kurgan & 1459 & 56 & 23 & 1538 \\
\hline
\end{tabular}

the total number of public motor transport (buses) and transport of road-municipal services (trucks) should be converted to run on natural gas. The number of vehicles potentially using natural gas as fuel will be taken as $2 \%$ (according to the total number of gas-cylinder vehicles in the world). Thus, the number of gas-cylinder vehicles running on natural gas by types of transport passing through the studied sections of roads can make (Table 4 ): 
TABLE 3: The predicted total daily traffic intensity in the directions.

\begin{tabular}{|l|c|c|c|c|}
\hline Highway & Cars pcs. & Trucks pcs. & Buses pcs. & Total \\
\hline P351 & 28469 & 3750 & 868 & 33087 \\
\hline P404 & 25951 & 3243 & 712 & 29906 \\
\hline E22 & 12839 & 1479 & 512 & 14830 \\
\hline Tyumen-Kurgan & 10910 & 434 & 155 & 11499 \\
\hline
\end{tabular}

TABLE 4: The predicted number of vehicles using natural gas as fuel by 2020.

\begin{tabular}{|l|c|c|c|c|}
\hline Highway & Cars pcs. & Trucks pcs. & Buses pcs. & Total \\
\hline P351 & 569 & 1125 & 260 & 1954 \\
\hline P404 & 519 & 973 & 214 & 1706 \\
\hline E22 & 257 & 444 & 154 & 855 \\
\hline Tyumen-Kurgan & 218 & 130 & 47 & 395 \\
\hline
\end{tabular}

\section{Conclusions}

The conducted experiment allowed us to confirm the hypothesis about the geographic location of CNG RS and their productivity in Tyumen proposed by us in [18], namely: 1. At the exit from Tyumen on the highway E22 near the CHPP-2 (the performance is 125 of conventional fillings). 2. At the exit from Tyumen on the highway P351 next to the s. Derbyshy (the performance is 250 of conventional fillings). 3. At the exit from Tyumen on the highway 404 near the s. Үar (the performance is 250 of conventional fillings). 4. At the exit from Tyumen on the highway "Tyumen-Kurgan" near the village Patrushevo (the performance is 125 of conventional fillings). The rational territorial and quantitative construction of CNG RS in Tyumen can lead to the growth not only of gascylinder buses and trucks, but also of cars, both urban transport and transit, passing through the considered highways.

In the future, the CNG RS locations in question can become part of the all-Russian (connecting the western and eastern regions of Russia, as well as the Northern territories of Western Siberia) and international (connecting Russia, Kazakhstan and China) "blue transport corridor". This development of the CNG RS network can also be facilitated by the ongoing development of a number of new gas fields in the eastern part of Russia (Chayandinskoye, Kovyktinskoye, Kshukskoye, Nizhne-Kvakchinskoye, 
Sakhalinskoye, etc.), the construction of the "Power of Siberia" gas transmission system and the commissioning of the "Sobolevo-Petropavlovsk-Kamchatsky", "SakhalinKhabarovsk-Vladivostok" gas pipelines and others. Expanding the use of natural gas by motor transport will reduce pollution of the environment by harmful substances emitted with exhaust gases.

\section{References}

[1] Gusev A.S., Suvorov A.A., Sulaymanov A.O. Using controlled shunt reactors for voltage sabilization on the example of real electric power system // IOP Conference Series: Materials Science and Engineering - Volume 93, 2015, 012016, doi:10.1088/1757-899X/93/1/012016.

[2] Model Year 2012-2016 Light-Duty Vehicle Greenhouse Gas Emissions Standards and Corporate Average Fuel Economy Standards. https://www.gpo.gov/fdsys/pkg/FR2010-05-07/pdf/2010-8159.pdf (accessed May 5, 2017).

[3] GOST R 52033-2003. Vehicles with gasoline engines. Emissions of pollutants with the exhaust gases. - M.: Standartinform, 10 p., 2007.

[4] Chainikov D., Chikishev E., Anisimov I., Gavaev A. Influence of ambient temperature on the $\mathrm{CO}_{2}$ emitted with exhaust gases of gasoline vehicles // IOP Conference Series: Materials Science and Engineering - Volume 142, 2016, 012109, doi: 10.1088/1757-899X/142/1/012109.

[5] List of countries by carbon dioxide emissions. [Electronic resource]: https://en.wikipedia. org/wiki/List_of_countries_by_carbon_dioxide_emissions (accessed May 3, 2017).

[6] NGV Statistics. [Elect. resource]: http://www.ngvjournal.com/ngv-statistics-2/ (accessed May 5, 2017).

[7] Chikishev E., Ivanov A., Anisimov I., Chainikov D. Prospects of and problems in using natural gas for motor transport in Russia // IOP Conference Series: Materials Science and Engineering - Volume 142, 2016, 012110, doi: 10.1088/1757-899X/142/1/012110.

[8] Lim, C., Kim, D., Song, C., Kim, J., Han, J., Cha, J.-S. Performance and emission characteristics of a vehicle fueled with enriched biogas and natural gases // Applied Energy - Volume 139, pp. 17-29, 2015, doi: 10.1016/j.apenergy.2014.10.084.

[9] Wang, R., Wu, Y., Ke, W., Zhang, S., Zhou, B., Hao, J. Can propulsion and fuel diversity for the bus fleet achieve the win-win strategy of energy conservation 
and environmental protection? // Applied Energy - Volume 147, pp. 92-103, 2015, doi: 10.1016/j.apenergy.2015.01.107.

[10] Pastorello, C., Dilara, P., Martini, G. Effect of a change towards compressed natural gas vehicles on the emissions of the Milan waste collection fleet // Transportation Research Part D: Transport and Environment - Volume 16, Issue 2, pp. 121-128, 2011, doi: 10.1016/j.trd.2010.09.002.

[11] Sahoo, B.B., Sahoo, N., Saha, U.K. Effect of engine parameters and type of gaseous fuel on the performance of dual-fuel gas diesel engines-A critical review // Renewable and Sustainable Energy Reviews - Volume 13, Issue 6-7, pp. 1151-1184, 2009, doi: 10.1016/j.rser.2008.08.003.

[12] Rose L., Hussain M., Ahmed S., Malek K., Costanzo R., Kjeang E. A comparative life cycle assessment of diesel and compressed natural gas powered refuse collection vehicles in a Canadian city // Energy Policy - Volume 52, pp. 453-461, 2013, doi: 10.1016/j.enpol.2012.09.064.

[13] The total energy consumption. [Elect. resource]: https://yearbook.enerdata.ru/ (accessed May 4, 2017).

[14] Ogunlowo, 0.0., Bristow, A.L., Sohail, M. Developing compressed natural gas as an automotive fuel in Nigeria: Lessons from international markets // Energy Policy Volume 76, pp. 7-17, 2015, doi: 10.1016/j.enpol.2014.10.025.

[15] Chinese, D., Patrizio, P., Bonotto, M. A service station location model to explore prospects and policies for alternative transport fuels: A case of CNG distribution in Italy // Advances in Intelligent Systems and Computing - Volume 262, pp. 71-84, 2014, doi: 10.1007/978-3-319-04630-3_6.

[16] Anisimov, I., Ivanov, A., Chikishev, E., Chainikov, D., Reznik, L. Assessment of gas cylinder vehicles adaptability for operation at low ambient temperature conditions // WIT Transactions on Ecology and the Environment 190 - Volume 1, pp. 685-695, 2014, doi: 10.2495/EQ140651.

[17] Mkrtychan Y.S. Basic principles of construction of city gas supply network for motor transport // Alternative fuel transport. - 2013. - № 3 (33). - pp. 10-14.

[18] Chikishev E., Chainikov D., Anisimov I. Increasing the use of natural gas on motor transport by an efficient location of the NGV RS (on the example of Tyumen) // IOP Conference Series: Earth and Environmental Science - Volume 50, 012004, 2017, doi: 10.1088/1755-1315/50/1/012004.

[19] Obukhova N.A., Tsarikov A.A. Analysis of the temporal unevenness of the loading of the street-road network by traffic flows in the cities of the Urals and Siberia 
// Topical issues of road design. - Ekaterinburg: OAO Giprodonii. - №5(64). - pp. $102-108$. 